\title{
LETRAS HUMANAS Y LETRAS DIVINAS EN EL HUMANISTA BARTOLOMÉ JIMÉNEZ PATÓN
}

\author{
SECULAR AND SACRED TEXTS IN THE HUMANIST SCHOLAR \\ BARTOLOMÉ JIMÉNEZ PATÓN
}

\author{
CAtalina Monserrat Roig \\ Universitat de les Illes Balears-IEHM
}

Recibido: 16/06/2020 Aceptado: 23/09/2020

\section{RESUMEN}

La obra filológica que Bartolomé Jiménez Patón (1569-1640) dedicó a la traducción y explicación de autores clásicos evidencia la religiosidad profundamente católica de su autor. Como analizaremos en este trabajo, el humanista, convencido defensor del uso de los textos paganos, los leyó desde su convicción religiosa, los cristianizó, interrelacionó con ellos las fuentes bíblicas y cristianas, y persiguió a través de los textos clásicos la moralización, el adoctrinamiento y el fomento de fe la católica.

Palabras clave: Bartolomé Jiménez Patón, Humanismo, Literatura clásica y bíblica, Tradición clásica

\section{ABSTRACT}

Bartolomé Jiménez Patón's philological oeuvre (1569-1640), dedicated to the translation and the study of classical writers, evidences the profound Catholic faith of the author. Thus, this study aims at analysing such fervour in the works of this humanist 
who, apart from being a staunch defender of the use of secular texts, interpreted those from his religious conviction, sought to evince their biblical and Christian sources, and sought to moralise, indoctrinate and spread the Catholic faith through these classical texts.

Keywords: Bartolomé Jiménez Patón, Humanism, Classical and Biblical Literature, Classical Tradition.

\section{INTRODUCCIÓN}

El humanista manchego Bartolomé Jiménez Patón (1569-1640) combinó la faceta de maestro con una dilatada labor intelectual que desarrolló especialmente en el campo de la gramática, la retórica, la dialéctica y la reforma de costumbres (Monserrat Roig 2019, 105-106). En este último ámbito se muestra profundamente moralista y un tenaz defensor de la ortodoxia católica (Garau 2012 y 2015). Sus textos están condicionados por una religiosidad católica que, tal y como era propio en la mayoría de los humanistas del siglo XVII español, determina su universo de creencias, íntimamente enraizadas en la espiritualidad que brota de Trento.

En pleno ambiente de la Contrarreforma, la verdad y el conocimiento no se pueden desligar de las Sagradas Escrituras ni de la interpretación oficial de la doctrina que propugna la Iglesia. Su religiosidad también se manifiesta en las obras que dedicó a la traducción y explicación de autores clásicos ya que en ellas Patón subordinó los textos paganos a los bíblicos y cristianos, los leyó desde su convicción religiosa, interrelacionó las fuentes clásicas y religiosas, y cristianizó los textos paganos, siguiendo así la estela, entre otros, de Erasmo, Vives o Lipsio, que tanto influyó en Sánchez de las Brozas, Quevedo o Lorenzo Palmireno. Analizar todos estos aspectos es el objetivo que guía este trabajo.

Centrados, pues, en la obra filológica de Jiménez Patón, estudiamos aquí una serie de textos que presentamos a continuación. Empecemos por la Cátedra de erudición, libro inédito del humanista y datado en 1628 (Madroñal 1993, 8993). El manuscrito, copia del siglo XVIII, consta de una prelección (ff. 1-10) y treinta lecciones (ff. 11-355v). De la primera a la vigesimosexta se tratan los convites romanos en sus más variados aspectos y se traducen la Sátira 11 de Juvenal y el capítulo 21 del libro 5 de los Geniales de Alejandro de Alejandro (lecciones vigesimoséptima y vigesimoctava). En las dos últimas, Patón se propone demostrar la utilidad que supone el conocimiento de los textos paganos 
(los humanos), para el entendimiento de los bíblicos y cristianos (los divinos). Así, en la lección trigésima ${ }^{1}$, compila los conocimientos que, a partir de las letras de los gentiles, ha expuesto en las lecciones anteriores con el propósito de evidenciar que estos sirven para entender mejor aspectos y costumbres de los banquetes a los que Cristo asistió y que los Evangelios narran.

Nos ocupamos también del "Libro decimosexto" de los Comentarios de erudición ${ }^{2}$, que presenta la traducción y el comentario del libro tercero de las Odas de Horacio, y de las Declaraciones magistrales, género literario propio de la época, y que Jiménez Patón también cultivó al publicar, entre 1627 y 1628, dieciocho dedicadas a Marcial, y en 1632, una centrada en la sátira sexta de Juvenal $l^{3}$.

\section{JUSTIFICACIÓN DEL USO DE LOS TEXTOS DE LOS GENTILES}

Al iniciar la lección vigesimonovena de la Cátedra de erudición, Patón explica la tarea que va a emprender, esto es, el comentario de Vulg. prov. 23, 20$21^{4} \mathrm{y}$, especialmente, la expresión dantes symbola y el término symbolum, apelando al acatamiento de una supuesta petición recibida, y, como no podía ser de otra manera, invocando la ayuda divina:

$\mathrm{Y}$, aunque parece osadía culpable que un profesor de letras humanas no deje esto para los intérpretes de las divinas, porque quien lo pregunta y pide hace alguna confianza de nuestros estudios y deseos, más quisimos obedecer que escusarnos, confiando en El que las lenguas de los niños hace elocuentes que

1 "Leción trigésima en que se confirma cómo sirven las humanas letras a las divinas, ejemplificado en esta dotrina de convites" (ff. 339v-355v). En la transcripción de los textos castellanos, seguimos el criterio de modernizar las grafías, siempre y cuando no afecten a la fonética de la época.

2 El humanista pretendía que los Comentarios de erudición recopilaran su obra completa, reunida en un conjunto de ocho tomos a cinco libros cada uno. De todos ellos, solo ha sido recuperado uno, que comprende los libros que van del decimosexto al vigésimo y cuyo manuscrito data de 1621 . Contamos con la edición crítica del primero de estos libros (Jiménez Patón 2010).

3 A partir de las referencias del propio maestro en diversas obras, Abraham Madroñal aporta los títulos de otras cuatro Declaraciones magistrales centradas en Marcial y que a día de hoy se encuentran perdidas (2009, 174-175).

4 Los autores latinos y los libros de la Vulgata se citan según el índice del Thesaurus Linguae Latinae (Lipsiae, in aedibus B. G. Teubneri, 1904). Los autores griegos siguen el Diccionario GriegoEspañol (Madrid, CSIC, 1980). Para los textos cristianos usamos la Patrologia Latina (PL) y la Patrologia Graeca (PG) de Migne. En los textos latinos y griegos citados a lo largo del trabajo, respetamos el texto de Patón siempre que concuerde con el texto o las lecturas de la edición oxoniense. En caso evidente de error, se ha restituido el texto mediante corchetes cuadrados o se han elidido con corchetes angulares los elementos sobrantes. 
ayudará la mía y mi entendimiento, aunque corto, para que satisfaga bajo de la censura católica y de los prudentes, repitiendo lo que a este propósito han dicho santos y doctos varones. (ff. 321-321v)

Con esta recusatio inversa nuestro autor busca la benevolencia en sus lectores, y nos atrevemos a afirmar que se sirve de ella no solo como recurso literario, meramente retórico, sino también alentado por su habitual prevención ante cualquier posibilidad de ser acusado de heterodoxia ${ }^{5}$. Debemos recordar que, en cierto modo, era garante de la ortodoxia al ser notario del Santo Oficio de la Inquisición de Murcia y este hecho condiciona en buena medida sus prevenciones en materia de fe.

No es de extrañar, pues, que en ese contexto de Contrarreforma, Jiménez Patón se arme con la autoridad que le confieren cuatro padres y doctores de la Iglesia, Basilio de Cesarea, Gregorio Nacianceno, Ambrosio de Milán y Agustín de Hipona, de los que, al principio de la lección trigésima de la Cátedra de erudición (ff. 339v-341v), selecciona fragmentos en los que se defiende el uso y el provecho de los textos de los gentiles ${ }^{6}$. Para ilustrarlo, ofrecemos la referencia a san Agustín:

San Agustín en sus libros De la ciudad y en otras muchas partes de sus obras dice mucho a nuestro propósito, pero de todo ello no repetiré más que dos bocados de los De la dotrina cristiana. Sea el primero del capítulo 28: Historia, dice, plurimum nos adiuuat ad sanctos libros intel[l]igendos, etiamsi praeter Ecclesiam puerili eruditione discatur" . "La Historia nos ayuda mucho para entender los libros santos aunque con erudición pueril se deprenda fuera de la Iglesia". Y en el capítulo 4 había dicho: Philosophi autem qui uocantur, si qua forte uera et fide[i] nostra[e] accommoda dixerunt, [maxime Platonici], non solum formidanda non sunt sed ab eis etiam tanquam ab iniustis posses[s]oribus in usum nostrum uendicanda ${ }^{8}$ ¿Qué dirá el melindroso $^{9}$ y que, de muy religioso, da en supersticioso, oyendo esto a tan gran sabio y no menor santo? Pues dice: "si acaso los que llaman filósofos dicen algunas cosas verdaderas y conformes a nuestra fe católica (principalmente

5 "Como sabemos que le sucedió al Brocense, al ser víctima de varios procesos inquisitoriales, fruto de su fidelidad a la teología de Erasmo" (Garau 2014, 105).

6 También en los mismos folios menciona a san Jerónimo de quien afirma: "De san Jerónimo no digo, porque de quien más tengo repetido en otras partes es este doctor máximo" (f. 341). Las referencias de los tres primeros autores son: Basil. Gent. 2 (PG 31, 567b-c); Gr.Naz. Oratio IV ${ }^{a}$. Adversus Julianum imperatorem prior Invectiva 51 (PG 35, 635b-c); Ambr. fid. 3, 1, 3 (PL 16, 589d-590b).

7 Aug. doctr. christ. 2, 28, 42 (PL 34, 55).

8 Aug. doctr. christ. 2, 40, 60 (PL 34, 63).

9 Melindroso: "El que afecta demasiada delicadeza en las acciones, o en el modo" (Aut.). 
los Platónicos) no solo no las hemos de huir y temer, pero las hemos de tomar y sacar de entre ellos como de injustos poseedores, y reducirlas a servicio y provecho nuestro". (ff. 341-341v)

Para el de Hipona, los conocimientos que transmiten la historia y la filosofía, esta última con ciertas prevenciones, deben ser aprovechados por los cristianos. La primera, asegura, ayuda a entender los textos sagrados - "los libros santos"y en el caso de la segunda, cuando lo afirmado por los filósofos concuerde con la verdad y la fe, debe ser recuperado por los cristianos, los únicos depositarios del verdadero conocimiento, para que sea aprovechado en la ilustración de la fe católica y en la defensa de la moral que propugna. Es este el valor de la auctoritas historiae humanae que reivindicó Melchor Cano (2006, 527-552 y 553666) décadas antes que Jiménez Patón y que implicaba que "toda la historia y la literatura profanas deben estudiarse para buscar en ellas testimonios que puedan fortalecer el dogma cristiano" (Curtius 1955, 768-769), un método que, como veremos a lo largo del trabajo y especialmente en $§ 5$, también fue adoptado por nuestro humanista ${ }^{10}$.

Jiménez Patón traduce seguidamente un pasaje del De doctrina christiana, en el que la erudición de algunos autores cristianos se atribuye a las letras humanas:

Y añade: “¿por ventura no advertimos y echamos de ver cuán cargado de oro y plata salió de Egipto Cipriano, doctor suavísimo y muy bienaventurado mártir? ¿Con cuán grandes riquezas salió Lactancio, cuán próspero Vitorino, Optato, Hilario?" (f. 341v) ${ }^{11}$

Como es habitual en la época, y nuestro autor no es en absoluto una excepción, Jiménez Patón en estos folios no es original ni en los autores citados ni en los textos reproducidos, ni tampoco lo es en la mayor parte de sus reflexiones o comentarios. Ciertamente, varios de los capítulos del Singularium locorum ac rerum libri quinque de Martinus de Roa son la fuente a partir de la cual Patón redacta las páginas iniciales de la lección trigésima. Se puede comprobar

10 "Es el mismo método empleado por los apologetas y los Padres pre-niceanos (sic), pero Cano lo incorporó al sistema de la teología. Esta ideología es típica de una posición espiritual universal y armonizadora, que se propone aprovechar todo el patrimonio espiritual, incluyendo el del paganismo, en favor de una filosofía cristiana de la cultura; es intolerante para con los herejes y los infieles, pero nunca para con los studia humanitatis. Esta actitud imprimirá también su sello en la literatura del Siglo de Oro español, poniéndola en violento contraste con el espíritu francés e inglés del siglo XVII" (Curtius 1955, 769).

11 Aug. doctr. christ. 2, 40, 61 (PL 34, 63). 
confrontando las citas agustinianas latinas o traducidas por Jiménez Patón con el texto del jesuita cordobés:

Multa hic in 2 De doctrina Christiana, sed libabo perpauca. Historia (inquit capite 28) plurimum nos adiuuat ad sanctos libros intelligendos, etiamsi praeter Ecclesiam puerili eruditione discatur. Capitulo autem 4: Philosophi autem (inquit) qui uocantur, si qua forte uera et fidei nostrae accommoda dixerunt, maxime Platonici, non solum formidanda non sunt sed ab eis etiam tanquam ab iniustis possessoribus in usum nostrum uendicanda. [...] Ac nonne, inquit, aspicimus quanto auro et argento et ueste suffarcinatus exierit Aegypto Cyprianus, doctor suauissimus et martyr beatissimus? Quanto Lactantius, quanto Victorinus, Optatus, Hilarius? (Roa 1604, 441-442) ${ }^{12}$

Patón reivindica a continuación a los autores cristianos que, mostrando en sus escritos también los saberes profanos, permitieron a la Iglesia y la fe católica erigirse en legítimas depositarias de la sabiduría que el paganismo había atesorado:

¿Qué diremos de Orígenes, Beda, Justino Mártir, Clemente Alejandrino, Eusebio Cesariense, Arnobio, Tertuliano y de otros muchos que con sus escritos, llenos de erudición sagrada y profana, fueron de grandísimo provecho a la Iglesia de Dios, sacando de poder de los injustos poseedores la sabiduría, y restituyéndola al verdadero que es la fe católica y santa? (ff. 341v-342) ${ }^{13}$

\section{ERUDICIÓN ACUMULATIVA Y CRISTIANIZACIÓN DE LOS CLÁSI- $\operatorname{COS}$}

Ya al inicio de la Cátedra de erudición, Patón justifica su estilo con estas palabras:

Me determiné a esta traducción y glosa en la manera que la experimentará el que lo leyere, por parecerme que así, diciendo lo necesario para entender al

12 El texto latino patoniano, como se puede constatar, se distancia del Singularium locorum únicamente en la referencia al De ciuitate, y en las reconstrucciones de intel[l]igendos -en el ms.: inteligendos-, de fide[i] nostra[e] -en el ms.: fide nostra-, de Aeg[y]ptiorum -en el ms.: Aegiptiorum-y de posses[s]oribus -en el ms.: possesoribus-, y en la omisión reconstruida de maxime Platonici que sí refleja la traducción del humanista.

13 La dependencia respecto del jesuita cordobés se percibe de manera clara con una simple confrontación de los dos textos: Quid Originem, Bedam, Iustinum Martyrem, Clementem Alexandrinum, Eusebium Caesariensem, Arnobium, Tertullianum, aliosque commemorem? quorum eruditio tantam rebus etiam sacris lucem attulit, quanta si caruisset Ecclesia, magno certe caruisset tum praesidio, tum etiam ornamento (Roa 1604, 442). 
poeta Marcial -que es cuyas epigramas principalmente se dec[lar]an ${ }^{14}$ y glosan-, se interpretan otros muchos autores, no haciendo haraganes los entendimientos, antes obligándoles a cuidado con la dependencia que unas cosas tienen de la apelación de otros lugares y citas de autores, engazándolos ${ }^{15} \mathrm{y}$ no ensartándolos ${ }^{16}$ con las advertencias y observaciones siguientes. (f. 1-1v)

Como era habitual en los humanistas de la época, Jiménez Patón pretende engalanar sus aportaciones con una pátina de erudición que ya Julio Caro Baroja $(1978,56)$ definió como método de la erudición "acumulativa", esto es, una exposición del saber atestada de referencias, que bien podían estar arrancadas de su contexto y sin que importara la época, el género literario o los autores ${ }^{17}$. Lo ilustramos con un pasaje de los Comentarios de erudición en el que, después del comentario de la oda 3, 11 de Horacio, nuestro autor recopila los tres tipos de mujeres que, según su carácter, aparecen en el poema:

Aquí nota el poeta tres condiciones de mujeres. Una, las doncellas zahareñas ${ }^{18}$ que aún para los maridos con quien las casan son ásperas, desdeñosas y mal acondicionadas, $\mathrm{y}$, si esto no pasase de los principios, no es malo, mas, si les dura espacio de tiempo, es aborrecido y odioso contra lo del Apóstol y el amor conyugal que deben; esta condición reprehende Horacio en Lide. Otra es la clase $<\mathrm{s}>$ de mujeres traidoras y aleves que no reparan en quitalles la honra y vida a sus maridos, por sus gustos de enojo o lascivia; estas fueron las hijas de Dánao. La tercera es de las que aman y quieren a sus maridos más que a sí mismas, pues aventuran su vida y libertad por ellos, como Hipermnestra por Lino y, en las divinas letras, Micol por el real profeta David, y otras muchas en las divinas y humanas. (172)

De acuerdo con el humanista, integran el primer tipo de mujeres aquellas "zahareñas" que, como Lide de la oda horaciana, por su natural esquivo e irreductible, actúan con desdén y sin afabilidad para con sus maridos, una actitud que, según Patón, no plantea problemas si se reduce a los momentos iniciales del matrimonio pero los crea cuando perduran, yendo en contra de lo que estableció San Pablo respecto de las relaciones y deberes conyugales ${ }^{19}$. En segundo

14 En el ms.: "decralan".

15 Engazar: "Trabar, encadenar una cosa con otra, uniéndolas entre sí por medio de un hilo de oro, plato o alambre" (Aut.).

16 Ensartar: "Por translación es encadenar una razón tras otra, sin a atender a estilo, método y orden, diciendo cuanto se ofrece y hablando continuamente sin reparar en cosa alguna" (Aut.).

17 Para el uso de este método en la obra no filológica de Jiménez Patón, cf. Garau (2014, $105-$ 110).

18 Zahareño: "desdeñoso, esquivo, intratable o irreductible" (DRAE).

19 Vulg. I Cor. 7, 1; Eph. 5, 22-24. 
lugar, están las mujeres traidoras, infieles, desleales y pérfidas, pues este es el significado de "aleves", que, de la misma forma que las hijas de Dánao mataron a sus esposos, estas no dudan en despojarles de su honra y, tal vez de la vida, movidas por su mal carácter y la tan anticristiana lascivia. Finalmente, aparecen las que, por amor a sus maridos, se sacrifican por ellos como en las letras humanas hizo Hipermnestra por Linceo, no Lino, un error de Patón advertido por los editores, y en las letras divinas, Micol por David ${ }^{20}$, al desobedecer ellas a sus propios padres, Dánao y Saúl, y ayudar a sus maridos a escapar de la muerte. Como vemos, las odas horacianas, los mitos griegos y los textos bíblicos se combinan para tratar la misma cuestión.

El acopio de referencias clásicas y bíblicas no tiene solo un valor estético o de ornato erudito sino que también actúa como recurso de autoridad ante los contenidos presentados. Así, por ejemplo, también en los Comentarios de erudición, para justificar que las bodas se celebraban de noche entre los antiguos, Patón recurre a once referencias: dos autores griegos (Plutarco y Homero), seis latinos (Plauto, Cicerón, Juvenal, Suetonio, Ausonio, Aulo Gelio y Claudiano) y dos libros del Antiguo Testamento (Jueces y Ester):

La causa porque se celebraban de noche las bodas, dejando muchas morales que da Plutarco en sus Problemas, la más cierta es porque las tales bodas siempre se han celebrado y celebran con banquetes y comidas espléndidas, y estas las celebraban los antiguos no al medio día, como nosotros, sino a la noche en la cena; y esto era común también a hebreos, griegos y latinos, como consta, porque en Homero celebra las bodas de noche con cena. Plauto dijo a este propósito: [Tu] miles, apud me cenabis, hodie fient nuptiae.

Cicerón, escribiendo a Quinto fratre, le dice: [...]. Juvenal, en su sátira sesta, también hace mención desta costumbre; Suetonio, en la Vida de Caligula; Ausonio, en la epístola a Plutarco [...]; Aulo Gelio. Y Claudiano [...]. En las divinas letras en el Libro de los Jueces [...]; y en Ester [...] (170-171) ${ }^{21}$.

En el último folio de la Declaración magistral de la epigrama de Marcial 122 , libro 14, dedicada al uso y significado de los anillos en el mundo grecorromano, incluso es el propio Patón quien explícitamente justifica su proceder y apunta la autoridad que confieren a sus escritos las referencias a las letras

20 Vulg. I reg. 19, 11-17.

21 Las referencias que anotan los editores son: Plu. Moralia 279 F; Hom. Od. 4, 305; Plaut. Curc. 728; Cic. ad Q. fr. 2, 3, 7; Iuu. 6, 202; Suet. Cal. 25, 1; Aus. Cento nuptialis o lib. 17, 2; Claud. Rapt. Pros. 2, 327; Vulg. iud. 14, 10 y una contaminatio de Vulg. Esth. 1, 3 y 2, 18. En relación a Aulo Gelio, afirman: "Gelio no toca este tema" (Jiménez Patón 2010, 170-171). 
humanas y divinas. Así, para confirmar el uso del anillo como prenda de amor o pacto, parte del verso 27 de la Sátira 6 de Juvenal, aporta un fragmento del martirio de Santa Inés y tres referencias veterotestamentarias:

Diose [el anillo] también por prenda y señal, como dijimos, y consta de Juvenal, Sátira 6: Et digito pignus fortasse dedisti. "Y presumo que ya le has dado a la novia el anillo nupcial, que esta es la prenda del dedo". Claro está que es el anillo, aunque no lo interpretara Británico ${ }^{22}$. Y no se teniendo por mezcla de erudición profana con divina hacer que sirvan las letras gentiles a las sagradas cuando se traen testimonios de todas en prueba de nuestro intento, más persuadiendo ${ }^{23}$ virtud que exhortando ${ }^{24}$ vicios, bien podemos apli$\mathrm{car}^{25}$ lo de santa Inés, virgen y mártir, cuando al mozo enamorado que la solicitaba respondió: Recede a me pabulum facinoris, quia iam ab alio amatore praeuenta sum, anulo suo subarrhauit me $e^{26}$ : "Otro amante divino me previno y me tiene prendada con su anillo". Como el anillo que dio en prendas a Tamar Judas, su suegro, que le valió no menos que la vida, Génesis $38^{27}$. Y con el que el padre del hijo pródigo mandó adornar en prendas de su amor al hijo restituido a su gracia ${ }^{28}$. Es con el que se adornó Judi $[t]^{29}$, para vencer a Holofernes, capítulo $10^{30}$. $\mathrm{Y}$ otros muchos lugares y autores divinos y profanos hay en que se prueba lo declarado en esta epigrama, pero no es posible decillo todo en un pequeño espacio. (f. $6 \mathrm{v})^{31}$

22 Britannicus (1551, 98 sv. pignus): Annulum, quo sponsus puellae digitum induit.

23 Persuadir: "Obligar a alguno con el poder de las razones o discursos que le propone, a que ejecute alguna cosa o la crea" (Aut.).

24 Exhortar: "Inducir y mover con razones y voces, animando y esforzando a otros para hacer alguna cosa" (Aut.).

25 Aplicar: "Vale comparar, asemejar, apropiar una cosa con otra, y traerla al propósito de lo que se hace o dice" (Aut.).

26 Berchorius (1589, 182E s.v. anulus). Si bien el martirio de santa Inés se narra en la Legenda Aurea de Jacobo de la Vorágine (Graesse 1850, 113-114), el texto reproducido procede del diccionario de Berchorius por la coincidencia del texto y las tres referencias bíblicas que Patón reproduce a continuación y que también se encuentran en la obra del benedictino francés.

27 Vulg. gen. 38, 18.

28 Vulg. Luc. 15, 22.

29 En el ms.: "Judi".

30 Vulg. Iudith 10, 3.

31 La autoridad de los clásicos también se aplica de manera recurrente a lo largo de su obra para justificar prácticas y comportamientos propios del catolicismo. Por ejemplo, en los Comentarios de erudición vincula las fiestas paganas dedicadas a los dioses agrícolas con las romerías de su época (pues este es el sentido del término 'velas'): "También hacían fiestas al Genio y a otros dioses propicios para la labranza acabado el agosto, encamarados los frutos -y aún nuestros labradores cristianos hacen las velas en las ermitas por este tiempo". (195) 
Además, del pasaje reproducido podemos colegir que la máxima de "más persuadiendo virtud que exhortando vicios" vincula la labor filológica con su voluntad constante de adoctrinamiento. En este sentido, el tratamiento de los textos de la Antigüedad clásica que muestran las obras de Jiménez Patón está claramente condicionado por su religiosidad y la subordinación de su ideal de vida y de virtud a sus creencias en materia de fe. Tanto es así que el humanista y maestro no duda en defender, recomendar y practicar la cristianización de los textos y los autores clásicos $^{32}$. Así, ya al inicio de la Cátedra de erudición, la reclama como obligación del maestro cristiano a la par que transluce un afán de moralización en los asuntos tratados y el adoctrinamiento en la fe católica, también constantes en sus obras y que no pueden ni deben desligarse del proceso de enseñanza:

En aquellas cosas que [los epigramas de Marcial] tuvieren alguna analogía y paridad con las nuestras, [es necesario] concordallas, que el precetor cristiano tiene obligación a cristianar las sentencias de los gentiles -en la manera que pueda- procurando en todas las leciones sacar alguna doctrina moral, pues es así que: Omnia quae scripta sunt, ad nostram utilitatem scripta sunt. (ff. 6$6 v)^{33}$

La cristianización no se limita a los textos clásicos -las "sentencias de los gentiles" de la cita anterior- sino que también afecta a los autores clásicos más insignes. Lo percibimos en el siguiente pasaje de los Comentarios de erudición cuando, al tratar la oda 3, 3 de Horacio y apuntar que los romanos se servían de la adivinación a través de las aves, bien por la ornitomancia, bien por los tripu$\operatorname{dios}^{34}$, afirma: "Y no puedo dejar de maravillarme de la ceguedad de esta gente en estas supersticiones vanas; y más habiendo disputado contra ellas los más doctos de sus repúblicas" (118-119). De los "más doctos" señala a Catón y, después, a Cicerón con estas palabras:

Cicerón, en los libros que hizo de adivinar, hace notable burla desto, y después de haber disputado, docta, aguda y evidentemente contra este yerro,

32 Como afirma Garau, Patón actuaría “en la línea de los consejos del famoso canonista Martín de Azpilcueta, para quien se había de explicar en clave cristiana a los autores gentiles" $(2014,104)$.

33 Esta última frase es una adaptación del texto de la Carta a los Romanos de san Pablo quaecumque enim scripta sunt ad nostram doctrinam scripta sunt (Vulg. Rom. 15, 4), que aparece en la explicación de Atto de Vercelli Expositio in epistolas sancti Pauli. In epist. Ad Rom. PL 134, 273b: Quaecunque enim scripta sunt, ad nostram utilitatem scripta sunt.

34 Comentarios de erudición, 118 "tres maneras de adivinar en las aves: por el vuelo a la mano izquierda o derecha, torcido o recto; por el canto; y por la comida, como era lo de los pollos". 
sintiendo la verdad como pudiera un docto católico, concluye con esto: Vides tamen omnia fere contraria ac dicta sint euenisse ${ }^{35}$. (119)

Cicerón es elevado a la categoría de los doctos católicos, pues, al igual que estos, puede percibir la verdad. Para el humanista católico del siglo XVII la Biblia es la fuente de todo conocimiento, y es en sus textos donde se encuentra la Verdad revelada. No es de extrañar, por tanto, que Patón interprete también las odas horacianas en clave bíblica y en consonancia con las Sagradas Escrituras. Lo ilustramos con la ética o moraleja a la oda 3, 8 de Horacio de los Comentarios de erudición. En el poema, Horacio explica a Mecenas que están celebrando el sacrificio de un cabrón blanco que el poeta debía a Baco por haberle salvado un año antes de morir aplastado por un árbol ${ }^{36}$. Patón concluye el comentario a la oda con estas palabras:

Aquí nos enseña el poeta cómo, en todos los acontecimientos buenos, hemos de dar gracias a Dios, reconociendo que de su mano nos viene todo el bien, según lo de la Escritura: "todo b[i]en dado deciende del Padre eterno, y todo don perfeto" 37 , porque el mundo no puede dar cosas de tal jaez, que todas las suyas son imperfectas. (163)

En la oda, el dios es Baco pero Patón lo convierte en el Dios cristiano al que se debe agradecimiento y ser consciente de la bondad y la perfección de sus dádivas.

\section{EL PROVECHO DE LAS HUMANAS Y DE LAS DIVINAS LETRAS}

Como ya hemos apuntado al inicio de este estudio, Jiménez Patón dedica las dos últimas lecciones de la Cátedra de erudición a demostrar que el conocimiento de los convites griegos y romanos, obtenido a partir de los textos paganos, permite entender los banquetes judíos y, especialmente, aquellos en los que Cristo participó ${ }^{38}$, mostrando cómo las letras humanas sirven para entender las letras divinas. De hecho, Patón explicita su intención en las últimas líneas de la lección vigesimoctava:

35 Cic. Diu. 2, 53. En las ed. modernas: fere contra.

36 Hor. carm. 3, 8, 6-8.

37 Vulg. Iac. 1, 17: Omne datum optimum et omne donum perfectum desursum est descendens a Patre (referencia no anotada por los editores de los Comentarios de erudición).

38 Cátedra de erudición f. 342: "todos los ritos y ceremonias de los antiguos romanos se hallaron en los que asistió e hizo Cristo, nuestro Bien, Señor y Maestro". 
Esto es lo que de las humanas letras hemos podido juntar de la costumbre y ceremonia de los antiguos romanos y de algunas otras naciones, que, mirado con la atención cristiana que conviene, ayuda, y no poco, a la inteligencia de las divinas letras, a las cuales han de servir las humanas para que su leción no sea odiosa, como se habrá esperimentado en algunas de las leciones pasadas. Y para mayor prueba, concluiremos las leciones deste libro con las dos que restan, ejemplificando más de propósito la verdad deste intento". (f. 320v)

Veamos un ejemplo. En la lección séptima había determinado que en los banquetes los romanos cenaban descalzos:

Al entrar a la sala del convite [...] se descalzaban [...]. Consta de Terencio en la comedia Heauton timorumeno $[s]$ acto 1 , escena 1 , donde dice el viejo:

accurrunt serui, soccos detrahunt, uide $[o]^{39}$ alios festinare, lectos sternere, coenam apparare $[\ldots]^{40}$

Nuestro Marcial dijo esto del descalzar [...]:

Deposui soleas, affertur protinus ingens inter lactucas oxigarumque liber. [ff. $64 v-65]^{41}$

Y en la lección trigésima, a partir de la costumbre romana, por un lado, y por el otro, del lavatorio de pies que hizo Jesús a los apóstoles (Vulg. Ioh. 13, 5) y de la unción de Jesús en casa de Simón el fariseo (Vulg. Luc. 7, 37-38), deduce nuestro autor que tanto los apóstoles como Jesús debían seguir la misma costumbre, estar descalzos, ya que, en caso contrario, no se hubiera producido ni el lavatorio ni la unción tal y como nos son narrados:

Y si los romanos se descalzaban para sus convites, que los discípulos cenasen descalzos consta, pues, para lavárselos, era forzoso estarlo, y de los mismo que le sucedió a la Madalena se infiere que lo estaba Cristo cuando con sus lágrimas comenzó a regar sus pies. (f. 347)

Como es sabido, los evangelios son presentaciones narrativas de la historia de Jesús y los motivos de la tradición de las comidas en las que participó derivan de los hábitos asociados a la comida formal grecorromana arquetípica: el banquete. Por tanto, en los Evangelios aparecen los motivos asociados al banquete grecorromano y a la tradición literaria del simposio ${ }^{42}$. El análisis de

39 En el ms.: uideas.

40 Ter. Haut. 124-126.

41 Mart. 3, 50, 3-4.

42 Smith (2009, 342-343): "Las comidas en las que Jesús participaba que los evangelios presentan contienen elementos típicos del banquete grecorromano y/o de la tradición del simposio. 
Patón, condicionado por su supeditación a la Verdad bíblica, infiere de los textos una verdad histórica que atribuirá a todo el pueblo judío, sin limitación cronológica, ni social, ni de ningún tipo.

Y si en los pasajes anteriores detectábamos el recurso a las letras humanas para explicar las divinas, ilustremos ahora el proceso contrario: recurrir a las letras bíblicas y cristianas para entender y confirmar lo expuesto en los textos paganos. Pues, como afirma nuestro humanista en la Declaración magistral de la epigrama de Marcial 69, libro 5:

Y no hay para que nadie se enfade de que, en leciones de humanidad, se apliquen lugares de erudición divina, pues -como hemos probado en otras ocasiones y dicho muchas veces- en esto la señora favorece a las siervas, y cuando las humanas letras se aplican para declarar las divinas, las siervas sirven a su señora. (f. 3$)^{43}$

Es el caso del siguiente pasaje de los Comentarios de erudición en que se citan dos versos de las Lamentaciones de Jeremías para confirmar la descripción de las lamias del heleno Dión Crisóstomo:

Crisóstomo Dión [sic] escribe que, en la interior de la África, [hay unas fieras] que tienen cara de mujeres hermosas y, así mismo, el pecho y tetas de tanta hermosura y belleza humana [...]. Y dice que se llaman lamias. Escondiendo la demás figura, que es de fiera particular, descubren el rostro y pecho y, con halagos mujeriles, atraen los caminantes que por allí pasan; y [...] en teniéndoles cerca, les cogen, despedazan y comen cruelmente ${ }^{44}$. Y parece que tiene fundamento de verdad porque Jeremías, en sus Trenos, dice:

Lamiae nudauerunt mamas nutriuerunt catul $<$ l>os suos. $(191)^{45}$

En la declaración antes citada, el humanista defiende que en Marcial el significado de 'lisonjear' de la expresión oleum ferre in auriculam ${ }^{46}$ se deriva del uso del acusativo auriculam y lo contrapone al de 'no escuchar' que implicaría la variante en ablativo, con la que ya vacilaban las ediciones contemporáneas.

Estos elementos incluyen aspectos como: reclinarse (Mc. 2, 15; 6, 39; 8, 6; 14, 3; 14, 18 [y los paralelos sinópticos]; Lc. 7, 36; 11, 37; 14, 7; 24, 30), el lavatorio de pies antes de reclinarse (Lc. 7, 44; Jn . 13, 3-5) la unción con perfumes (Mc. 14, 3), recitar plegarias antes del deipnon (Mc. 6, 41; 8, 6-7; 14, 22), la colocación en la mesa (Lc. 14, 7) y en el simposio (Mc. 14, 23), acabar la comida con un himno (Mc. 14, 26), y un anfitrión, entre otros aspectos literarios".

43 En las ediciones modernas el epigrama del título corresponde a Mart. 5, 77.

44 D. Chr. 55, 11.

45 Vulg. thren. 4, 3.

46 Mart. 5, 77, 2: qui te ferre oleum dixit in auricula. 
Para justificar su defensa del acusativo, reproduce diversos ejemplos de textos paganos y bíblicos que concuerdan con su interpretación. Así, entre otros textos bíblicos, cita un pasaje de Oseas:

Oseas usó de la frasis de nuestro poeta en la misma sinificación de 'lisonjear' y con la misma construcción de acusativo, hablando de Efraín, capítulo 12, dándole nombre de 'lisonjero', dijo "se sustentaba del viento", como el camaleón, que es figura de tal. Ephraim pascit uentum [...] et oleum in Aegyptum ferebat $^{47}$. "Efraín dio en seguir las vanidades [...] y lisonjeó a los gitanos ${ }^{48}$ ". (f. $2 \mathrm{v}$ )

A continuación, trata los sentidos figurados de sensualidad y alegría que el término oleum tiene en los textos bíblicos aportando un considerable número de ejemplos. Hasta que afirma:

Y pues consta que los gentiles tomaron de los sagrados libros, y en especial estas frases, oleum ferre in auriculam por 'lisonjear' y 'engañar', que todo es uno, como constó del testimonio de Oseas, muchísimos años antes que Marcial. (f. 3)

El razonamiento deja atónito al lector moderno, pues implicaría que los autores clásicos conocieran los textos sagrados en latín siglos antes de que se tradujeran a esta lengua. Para entender el porqué de tal afirmación debemos asumir que, para el fervoroso católico que era nuestro autor, los textos bíblicos eran los depositarios de la verdad, eran ellos también los que aportaban luz a los textos paganos y, por tanto, la cuestión temporal carecería de cualquier importancia.

\section{MORALIZACIÓN, ADOCTRINAMIENTO Y FOMENTO DE FE LA CA- TÓLICA}

La erudición acumulativa que tratábamos en $\delta 3$ tiene en el caso de Jiménez Patón no solo una función de ornato con un mero valor estético sino que también pretende servir de autoridad de la moral defendida (Garau 2014, 108) y resulta especialmente evidente en aquellos pasajes en los que, como casi siempre en nuestro autor, subyacen la moralización, el adoctrinamiento o el fomento de fe la católica. Lo ilustramos con un fragmento de la Cátedra de erudición en el que retrata los convites como el lugar ideal para caer en los más variados pecados.

48 Con 'gitanos' se refiere Patón a los egipcios. 
En convites de gente moza que pocas o ninguna vez (como dijo san Gregorio) escapan sin pecado, porque antes parece se juntan de industria a cometellos, porque además de que del mucho comer y beber se sigue el de la gula, en calentándoseles el estómago y el celebro, se desmanda la lengua y se descubren faltas ajenas ${ }^{49}$. Y aún de estas demasías se engendran los apetitos de la sensualidad como lo dijo san Pablo, que en el mucho beber se halla este vi$\operatorname{cio}^{50}$. [...] Corren parejas en causar daños el vino y la lujuria y [...] traen a ellos la causa desta desventura como lo son mujercillas livianas con ocasión de que dancen, bailen o canten, como lo celebra Horacio, murmura Juvenal y lo ríe Marcial. (ff. 337v-338)

De aquí que aconseje la moderación en la asistencia a ellos: "Palabras son que obligan a tenernos a raya en semejantes entretenimientos y a que con mucho tiento y recato asistamos en convites cuando fuere casi forzoso" (f. 337-337v).

De hecho, Patón tiene la habilidad de aprovechar cualquier oportunidad que le brindan los textos clásicos para extraer sus lecturas morales a pesar de que estos puedan parecer del todo alejados temáticamente de su posible moralización. Así, por ejemplo, dedica la lección novena de la Cátedra de erudición (ff. 76v-85v) a comentar algunos aspectos del acto de brindar en los banquetes romanos, empieza la lección con el comentario del epigrama 170 del libro 14 de Marcial, titulado signum uictoriae y escrito, según Patón, a propósito de la victoria del emperador Domiciano sobre los "alemanes" (f. 76v). Después de dieciocho folios concluye la lección apelando al necesario agradecimiento a Dios ante las victorias conseguidas contra los enemigos de la fe, tan propias de su tiempo, y la encomienda a Dios en todos los acontecimientos:

Desta epigrama declarada hemos de inferir la obligación que nos corre, no de celebrar las vitorias que nuestros ejércitos alcanzan de los enemigos de nuestra santa fe con espléndidos banquetes, antes con alegría cristiana, dándole a Dios gracias, en cuyo nombre y por cuya virtud se alcanzan. [...] Y lo mismo debemos hacer en cualesquier otras en particular y en general, mostrándonos agradecidos a nuestro verdadero Dios de las batallas y ejércitos, a quien, para tenellos buenos, hemos de encomendar nuestros sucesos. (ff. 85-85v)

También el adoctrinamiento y la moralización a partir de los autores clásicos resulta inevitable cuando trata cuestiones relacionadas con la mitología y la religión pagana. Es el caso de las páginas que en los Comentarios de erudición

50 Vulg. Eph. 5, 18: et nolite inebriari uino in quo est luxuria. 
dedica a la oda 3, 18 de Horacio ${ }^{51}$. El contenido del poema latino se divide en dos partes: el canto de invocación a Fauno y la descripción de las fiestas que en su honor se celebraban en Mandela ${ }^{52}$. Aunque por la oda horaciana se podría esperar un comentario centrado en el dios Fauno o en otras figuras mitológicas, en su lugar el autor se ocupa de los demonios, a los que identifica con los dioses adorados por los paganos, y de monstruos engendrados contra el orden natural. Al final del comentario, fiel a su voluntad constante de adoctrinamiento y de fomento de la devoción cristiana, exhorta a los católicos a que, tomando ejemplo de los gentiles, actúen con el mismo fervor en sus fiestas religiosas:

Desta oda ha de sacar confusión el católico viendo cómo los gentiles, con toda puntualidad y cuidado, celebraban las fiestas a estos portentos y monstros diabólicos; $\mathrm{y}$ ha de acusar y enmendar su descuido en la celebridad de las fiestas del verdadero y único Dios Trino y Uno, y de sus santos, porque uno de los pecados porque creen siervos de Dios y doctos varones que vienen malos temporales, esterilidad y miseria, así en cosechas como en crías, es el quebrantamiento de las fiestas. (208)

Las palabras de Jiménez Patón no pueden desvincularse de la época de rigor contrarreformista en que vivió, como prueba el alentar a celebrar las fiestas dedicadas a Dios, "el verdadero y único Dios Trino y Uno" del concilio tridentino, y, especialmente, las dedicadas a los santos pues su culto se consideraba prueba del seguimiento de la ortodoxia católica frente a las creencias protestantes.

\section{FINAL}

En estas páginas hemos mostrado cómo Jiménez Patón se posiciona a favor del uso de los textos paganos al defender que su conocimiento es necesario para entender los textos sagrados; además reivindica que el contenido de los textos de la Antigüedad debe ser aprovechado para la ilustración de la fe y la defensa de la moral católica pues propugna que la Iglesia es la legítima depositaria de la sabiduría que durante siglos habría acaparado el paganismo.

En nuestro autor el método acumulativo de la erudición tiene más que un valor estético y de ornato al actuar también como un recurso de autoridad para los contenidos expuestos, unos contenidos que son cristianizados sin contención alguna e interpretados en clave bíblica y en consonancia con las Sagradas Escrituras.

51 Jiménez Patón (2010, 200-209).

52 Pequeña aldea cerca de la villa que Horacio poseía en la región sabina. 
Por otro lado, Jiménez Patón interrelaciona las fuentes paganas y las religiosas bajo el pretexto de un provecho mutuo: las primeras, las humanas, como demuestra en la Cátedra de erudición, ayudan a la comprensión de las segundas, las divinas; y estas últimas, en tanto que depositarias del auténtico conocimiento, confirman y autorizan aquellas.

Como se ha ilustrado, incluso en la obra filológica se detecta de manera constante la voluntad de moralización, adoctrinamiento y fomento de la fe católica, y es precisamente en la Antigüedad, en el mito y sus protagonistas, y en la religión pagana donde nuestro humanista persigue la autoridad para justificar sus creencias y las prácticas religiosas que con tanto fervor defiende.

\section{REFERENCIAS BIBLIOGRÁFICAS}

Berchorius, Petrus. 1589. Dictionarii seu repertorio moralis Petri Berchorii Pictaviensis Ordinis Divi Benedictini. Pars prima. Venetiis: Apud Gasparem Bindonum.

Britannicus, Ioannes. 1551. Iunii Iuvenalis et A. Persii Flacci satyrae cum doctissimorum virorum commentariis atque annotationibus. Basileae: Froben.

Cano, Melchor. 2006. De locis theologicis. Editado por Juan Belda Planas. Madrid: BAC.

Caro Baroja, Julio. 1978. Las formas complejas de la vida religiosa: religión, sociedad y carácter en la España de los siglos XVI y XVII. Madrid: Akal.

Ciacconius Toletanus, Petrus. 1588. De triclinio romano. Fului Ursini Appendix. Romae: In aedibus S.P.Q.R, apud Georgium Ferrarium.

Curtius, Ernst Robert. 1955. Literatura europea y Edad Media latina. México, D.F.: FCE.

Garau, Jaume. 2012. "Ideas religiosas del Maestro Bartolomé Jiménez Patón (1569-1640) en El virtuoso discreto [c. 1629-1631]". Hispania sacra 64, n. 129: $237-258$.

Garau, Jaume. 2014. "La autoridad de los clásicos en la obra no filológica de Bartolomé Jiménez Patón". En La Autoridad en la Antigüedad, editado por Christoph Strosetzki, 99-127. Madrid-Frankfurt am Main: Universidad de Navarra-Iberoamericana-Vervuert.

Garau, Jaume. 2015. "La figura del orador cristiano en el Perfecto predicador (1612) de Bartolomé Jiménez Patón". Criticón 124: 137-152.

Graesse, Theodor, ed. 1850. Jacobi a Voragine Legenda aurea vulgo historia lombardica dicta. Editio secunda. Lipsiae: Impensis Librariae Arnoldianae. Jiménez Patón, Bartolomé. Cátedra de erudición repartida en treinta lecciones, 1628 , ms. siglo XVIII.

Jiménez Patón, Bartolomé. s.a. Declaración magistral de la epigrama de Marcial 69 , libro 5. ¿Madrid? 
Jiménez Patón, Bartolomé. s.a. Declaración magistral de la epigrama de Marcial 122, libro 14. ¿Madrid?

Jiménez Patón, Bartolomé. 2010. Comentarios de erudición ("Libro decimosexto"). Edición crítica, introducción y notas de María del Carmen Bosch Juan, Jaume Garau Amengual, Abraham Madroñal Durán y Juan Miguel Monterrubio Prieto. Madrid-Frankfurt am Main: Iberoamericana-VervuertCSIC. Ms. de 1621.

Madroñal, Abraham. 1993. "Aportaciones al estudio del maestro Jiménez Patón (dos obras inéditas y casi desconocidas)". Criticón 59: 83-97.

Madroñal, Abraham. 2009. Humanismo y Filología en el Siglo de Oro. En torno a la obra inédita de Bartolomé Jiménez Patón. Madrid-Frankfurt am Main: Iberoamericana-Vervuert.

Monserrat Roig, Catalina. 2019. "El vino y el agua en los convites romanos según la Cátedra de erudición (1628) del humanista Bartolomé Jiménez Patón”. En Aigua i vi a les literatures clàssiques i la seua tradició, editado por Juan José Pomer $y$ Helena Rovira, 105-120. Reus: Rhemata.

Roa, Martinus de. 1604. Martini de Roa cordubensis ex Societate Iesu Singularium locorum ac rerum libri quinque. Lugduni: Sumptibus Horatii Cardon.

Smith, Dennis E. 2009. Del simposio a la Eucaristía: el banquete en el mundo cristiano antiguo. Navarra: Editorial Verbo Divino.

Catalina Monserrat Roig Instituto de Estudios Hispánicos en la Modernidad (IEHM) Universitat de les Illes Balears Edificio Ramón Llull Ctra. de Valldemossa, km. 7.5 Palma de Mallorca (España) https://orcid.org/0000-0003-0672-108X 